\title{
A Look into the Triggering of Presuppositions in Chinese and English
}

\author{
Lei Kong \\ College of Foreign Languages, Qufu Normal University, Qufu, China
}

\begin{abstract}
The paper discusses the essential properties of presupposition and then makes a comparative analysis of Chinese and English presupposition triggers. The paper finds that while many presupposition-carrying expressions are semantically and pragmatically the same in English and Chinese, the realization of presupposition expressions may differ in the two languages.
\end{abstract}

Index Terms - presupposition, essential properties, presupposition triggers, English, Chinese

\section{INTRODUCTION}

Presupposition is a topic widely studied in the field of linguistics. It originated in the tradition of philosophy and then came into the field of linguistics. In this paper I will mainly discuss the properties of presupposition, and attempt to make a comparison between Chinese and English presupposition triggers. The organization of the article is as follows. Section 1 introduces the definition and three conceptions of presupposition; Section 2 discusses the properties of presupposition, covering constancy under negation, defeasibility, context sensitivity and culture sensitivity. Section 3 presents a comparative analysis of Chinese and English presupposition triggers.

\section{WhAT Is PRESUPPOSITION?}

A simple and informal definition for presupposition can be seen in Huang (2009, p.65), where it is defined as "an inference or proposition whose truth is taken for granted in the utterance of a sentence. The main function of presupposition is to act as a precondition of some sort for the appropriate use of the sentence. This background assumption will remain in force when the sentence that contains it is negated".

In some respects, presupposition seems free of contextual effects; in other respects, though, presupposition seems sensitive to facts about the context of utterance (Saeed, 2000, p.93). Theretofore, some linguists (for example Leech, 1981) have divided presupposition into two types: semantic presupposition and pragmatic presupposition. The former analyzes presupposition from the aspect of logic and semantics, amenable to truth-relations approach; the latter requires an interactional description. Stalnaker (1974) and Sperber and Wilson (1995) contend that presupposition is essentially a pragmatic phenomenon: part of the set of assumptions made by participants in a conversation (see Levinson, 1983; Saeed, 2000). Besides the above-mentioned two conceptions, there is a third version of presupposition which stands between the two: the view that presupposition involving both linguistic forms (i.e. sentences) and language users (i.e. speakers) should be called semantic-pragmatic (Karttunen, 1973, 1974; Soames, 1982) ${ }^{1}$.

Let us now take a look at the sources of presuppositions, i.e. the presupposition triggers. As for the number of triggers in our language, different linguists may offer different lists. For instance, Karttunen has collected thirty-one kinds of such triggers (Levinson, 1983, p.181), Levinson (1983, p.181-184) offered a list of 13 major types, and Huang (2009, p.65-67) distinguished two types of presupposition triggers: lexical triggers (e.g. definite descriptions, factive predicates, aspectual/change of state predicates, iteratives and implicative predicates) and constructional triggers (e.g. temporal clauses, cleft sentences and counterfactual conditionals). Besides what has already been mentioned, Levinson (1983, p.184) proposes other triggers of presupposition which seem to receive less attention. For example, manner adverbs generally trigger presuppositions. The little girl smiled / didn't smile cautiously will presuppose The little girl smiled. Presupposition triggers may show differences across languages. A detailed comparative analysis of Chinese and English presupposition triggers will be made in Section 3.

\section{PROPERTIES OF PRESUPPOSITION}

The most notable properties of presupposition are: (i) constancy under negation and (ii) defeasibility (Huang, 2009, p.67). In addition, sometimes presupposition is (iii) context sensitive and (iv) culture sensitive (i.e. the same utterance may contain different presuppositions for people in different cultures). In what follows, I'll detail the four properties.

A. Constancy under Negation

\footnotetext{
${ }^{1}$ Also see Huang Yan (2009, p.90).
} 
By constancy of negation we mean a presupposition generated by the use of a lexical item or a syntactic structure remains true when the sentence containing that lexical item or syntactic structure is negated (Huang, 2009, p.67). This property of presupposition can be expressed in the following truth relation:

a. If $p$ (the presupposing sentence) is true then $q$ (the presupposed sentence) is true.

b. If $p$ is false, then $q$ is still true.

Representative examples are given below:

(3.1) The Martians are welcome / are not welcome here 2 .

> There exist Martians.

(3.2) If I were in charge of the universe, I would / wouldn't arrange for my family to receive free Super Bowl tickets. $\left(\mathrm{COCA}^{3}\right)$

> I am not in charge of the universe.

The positive and negative versions of (3.1) and (3.2) contain the same presupposition, so negating the presupposing sentence does not affect the presupposition.

There are, however, problems at the heart of the notion of constancy under negation (Huang, 2009, p.68). Firstly, there is a class of sentences which are hard to negate, as in (3.3), where constancy of negation may not be necessary; secondly, constancy under negation may not be sufficient (Huang, 2009, p.68), as in (3.4a) (3.4b) (3.5).

(3.3) May our friendship last long!

> There is friendship between us.

(3.4a) Do / don't come and meet your guest. (COCA)

?>> Your guest is here.

(3.4b) Do / don't have another piece of banana bread. (COCA)

?> There is banana bread here.

(3.5) 您 ${ }^{4}$ 说 吧, 我这儿有问必答。 $\left(\mathrm{CCL}^{5}\right)$

Nin shuo ba, wo zher youwenbida.

YOU say-BA, I here answer all the questions.

I'll answer all the questions YOU ask.

?>> The addressee is socially superior to or distant from the speaker.

Although (3.4a) (3.4b) (3.5) satisfy the condition of constancy under negation, the inference in (3.4a) (3.4b) is analyzed as felicity condition on the speech act of requesting and in (3.5) as a conventional implicature (see Levinson, 1983, p.185; Huang, 2009, p.68).

\section{B. Defeasibility}

Like conversational implicatures, presuppositions are cancellable. They are annulled if they are in conflict with (i) back ground assumptions, (ii) conversational implicatures, (iii) certain discourse contexts, and furthermore (iv) certain intra-sentential contexts.

\section{Inconsistency with background assumptions}

Presuppositions are sensitive to background assumptions about the world. Compare (3.6) and (3.7).

(3.6) The situation worsened before it improved.

>> The situation improved.

(3.7) The toddler was caught by his mother before he fell down the stairs.

> P The toddler fell down the stairs.

The temporal clause, here in sentence (3.6) before it improved presupposes the situation improved. But the temporal clause in (3.7) before he fell down the stairs does not make the sentence carry the presupposition that the toddler fell down the stairs. This is because the putative presupposition conflicts with our world knowledge that once a baby falling down the stairs is caught, he/she couldn't fall down. Consequently, the presupposition is cancelled.

Now let's compare (3.6) with (3.8). The use of modal verb 'may' in (3.8) seems to make the presupposition impossible. The possible reason may be that the word 'may' is a non-factive verb that just expresses the uncertainty of the speaker, thus reduces the truth value of the complement.

(3.8) The situation may worsen before it improves.

>> The situation improves.

\section{Inconsistency with conversational implicatures}

Presuppositions can be defeated by inconsistent conversational implicatures, as is illustrated in (3.9).

(3.9) If he and his family can have a normal, free life in the United States with their safety ensured I will feel happy that they can achieve this.

\footnotetext{
2 This example and others without source of information are created by the author of the present article. Others with source of information are noted by putting the source in the parentheses immediately after the example.

3 http://corpus.byu.edu/coca/

${ }^{4}$ A respectful form of address of the second singular personal pronoun "you".

${ }^{5}$ http://ccl.pku.edu.cn:8080/ccl_corpus/index.jsp?dir=xiandai
} 
+> Perhaps he and his family can have a normal, free life in the United States with their safety ensured, perhaps they cannot.

> > He and his family have a normal, free life in the United States with their safety ensured.

The use of the factive predicate feel happy that in (3.9) should give rise to the potential presupposition that he and his family have a normal, free life in the United States with their safety ensured. However, there is also a Q-clausal conversational implicature due to the conditional (if $\mathrm{p}$ then $\mathrm{q}$ ), namely, perhaps he and his family can have a normal, free life in the United States with their safety ensured, perhaps they cannot. With such contradictory conversational implicature, the putative presupposition here is defeated.

\section{Inconsistency with certain discourse contexts}

Presuppositions are contextually defeasible.

(3.10) There are no Martians. Therefore, the Martians are not welcome here.

>> There exist Martians.

(3.11) (A says to the three people living in the boarding house)

A: Mr. Wainwright was killed between ten minutes past eight and ten minutes past nine, so anyone who can prove his alibi during all that time should have no worry.

B: It wasn't me who killed him. At half past eight I had a cup of coffee at the coffee-stall in Junkers Street. That's over a mile away. It's not proof, I admit, but they know me there, you see, and it may help. And it wasn't Mr. Calthrop who killed him. He was helping Mrs. Mayton with the curtain of the landing window. It had come off some of its hooks. And it wasn't Mrs. Mayton who killed him because she was fixing the curtain together with Mr. Calthrop. And I think nobody in the boarding house killed Mr. Wainwright. (A short story from Contemporary College English: Book 3, with some change for the convenience of analysis)

$\sim>$ Someone in this boarding house killed Mr. Wainwright.

(3.12) A: Has Mary's brother got divorced with his sadistic wife?

B: We should ask Mary because she is the only person who would know for sure.

C: I've asked her and she didn't know that her brother got divorced. So I think her brother is still enduring the torment of his marriage.

(3.13a) I don't know that my sister got married.

?>> My sister got married.

(3.13b) You / they don't know that my sister got married.

$>$ My sister got married.

In (3.10), the second sentence should presuppose that there are Martians. However, this putative presupposition is in conflict with the preceding proposition, namely, there are no Martians. As a result, the putative presupposition dissolves in the discourse context.

In (3.11), the conversational implicature in A's utterance is that someone in the boarding house killed Mr. Wainwright. In B's utterances, he used a lot of cleft sentences that all bear the presupposition that someone killed Mr. Wainwright. But the actual purpose of B is to convince A that all people in the boarding house all had their alibi, thus nobody in the boarding house killed Mr. Wainwright. In this case, the presupposition is suspended by the reduction arguments - arguments that proceed by eliminating each of the possibilities in a discourse (Huang, 2009, p.70).

In (3.12), C's utterance that she didn't know that her brother got divorced contains the epistemic factive predicate know. As a presupposition trigger, factive predicates usually presuppose the truth of their complements, in this case, namely, that her brother got divorced. However, the use of factive predicates in this case does not. This is because the presupposition is inconsistent with the whole of C's argument that since Mary is the person who would know her brother's state of marriage for sure, and since she didn't know that her brother got divorced, her brother did not get divorced. The presupposition is canceled in this case because the evidence for its truth is weighted and rejected (Huang, 2009, p.71).

But note that (3.13a) and (3.13b) form a contrast. Though sentence (3.13a) and sentence (3.13b) are structurally the same, sentence (a) does not have the presupposition that my sister got married as (b) does, which is because the presupposed sentence is inconsistent with the entailment of (a), namely, "as far as I know it is not the case that my sister got married". According to Huang (2009, p.70), when the factive predicates are used together with second / third person subject, the presupposition can often get through, while when they are used with first-person subject, presupposition sometimes drops out.

\section{Inconsistency with certain intra-sentential contexts}

Presuppositions can be blocked in certain intra-sentential contexts, that is, they can be defeated by using another clause in the same complex sentence to increment the local, intra-sentential context. There are mainly three subtypes of intra-sentential block of presupposition: (i) overt denial in co-ordinate clauses without apparent contradiction (see examples 3.14a and 3.14b below), (ii) explicit suspension by an if clause that follows (see example 3.16 below), and (iii) by verbs of saying (e.g. say, mention, tell, ask, announce) and verbs expressing propositional attitude (e.g. believe, think, imagine, dream, want) (see example 3.17 and 3.18 below).

(i) overt denial in co-ordinate clauses without apparent contradiction

(3.14a) The water is not boiling, in fact it is not even hot. 
>> The water is hot.

(3.14b) The Martians are not welcome here - there are no Martians.

> There are Martians.

The negation involved in overt denial of presupposition in (3.14a) and (3.14b) are generally considered as metalinguistic negation. It should be noted that positive sentences are much harder, if not impossible, to be overtly denied. Contrast (3.14a) (3.14b) with (3.15a) (3.15b).

$(3.15 \mathrm{a}) *$ The water is boiling, in fact it is not even hot.

$(3.15 b) *$ The Martians are welcome here - there are no Martians.

(ii) explicit suspension by an if clause that follows

(3.16) I bet 500 pounds that the German Football will win, if I have 500 pounds.

> > I have 500 pounds.

(iii) by verbs of saying and verbs of propositional attitude

(3.17) He said / told / informed me that the seller convinced the customers of the products value.

>> The seller tried to make the customers believe the products value.

(3.18) He imagined / dreamed that he is the master of the universe.

$\sim>$ There is a master of the universe.

As pointed by Green (1996), the verbs of saying and verbs of propositional attitude are "world-creating" words. They can define worlds other than the real world. The use of these words might lead to the block of presupposition (also see Huang 2009, p.73).

\section{Context Sensitivity}

The defeasibility character of presuppositions implies that often presuppositions seem sensitive to context. Different levels of context can cause fluctuations in presuppositional behavior ${ }^{6}$ (Saeed, 2000, p.100). Presuppositions are likely to be cancelled under certain discourse and inter-sentential ${ }^{7}$ contexts (see sections 3.2.3 and 3.2.4).

Take the English word leak as an example, semantically, leak is neutral, its negative meaning can only be derived from the context in which it is used, as shown in (3.19).

(3.19) As soon as the Times report appeared, Congressional leaders demanded a criminal probe, and president Obama said he had "zero tolerance" for "these kinds of leaks."

In this example, leak presupposes a criminal act.

In Chinese, however, there seems to be no such a neutral word, we can either use a positive 解密(jiemi, decipher) or a negative 泄密(xiemi, betray confidential matters). Interestingly, WikiLeaks is rendered into Chinese 维基解密 (wikijiemi), not 维基泄密 (wikixiemi) because 泄密(xiemi, betray confidential matters) usually presupposes a crime or an immoral act.

Furthermore, context sensitivity can be seen in the use of intonation in English and other languages, where the stress on different elements of the sentence can yield different presuppositions. Using capitals to show the stress, we can produce different presuppositions with examples (3.20a-c).

(3.20a) JACK loves Jill.

>> Someone loves Jill.

(3.20b) Jack loves JILL.

>> Jack loves someone.

(3.20c) Jack LOVES Jill.

>> Jack holds certain emotion toward Jill.

\section{Culture Sensitivity}

Culture can also be regarded as a contextual factor in its broadest sense. Here we separate it from other contextual factors and treat it as an independent property of presuppositions. Culture plays an important role in the understanding of presuppositions. Presuppositions about the reality familiar to one language community may be strange and new to another community, which may cause a gap in cross-cultural communication.

(3.21) She wore dark Cleopatra eyeliner and blue eye shadow and ironed her long blonde hair. (COCA)

Here in (3.21), a proper name Cleopatra was used. A proper name has many associations and it is culture-specific. As far as Cleopatra is concerned, she was the last pharaoh of Ancient Egypt. She remains a popular figure in Western culture. In most depictions, Cleopatra is portrayed as a great beauty, and her successive conquests of the world's most powerful men are taken as proof of her aesthetic and sexual appeal. So if we don't know the cultural presupposition of Cleopatra, we can't understand the presupposition in (3.21).

In the same way, a Chinese expression like 杜鹃花被人们誉为花中西施 (Rhododendron is regarded as Xi Shi ${ }^{8}$ of flowers) also triggers such presupposition peculiar to Chinese culture.

\footnotetext{
${ }^{6}$ At the most general level, the context provided by background knowledge; then, the context provided by the topic of conversation; and the narrower linguistic context of the surrounding syntactic structures - all can affect the production of presuppositions Saeed (1997, p.100-101).

7 The inter-sentential contextual feature is traditionally called the projection problem, and is discussed in Gazdar (1979) and Levinson (1983); also see Saeed (1997)
} 


\section{A COMPARAtive ANALysis OF ENGLiSh AND CHINESE PresupPositions}

According to He (1988, p.119), presupposition-triggers which include most of the presupposition-carrying expressions are essentially the same in English and Chinese. But the specific linguistic forms of presuppositional expressions may differ in the two languages. Below is a brief list of their similarities and differences in presupposition triggering.

\section{(i) Definite descriptions}

Like English, Chinese definite descriptions can also trigger presuppositions (see example 4.1).

(4.1a) Qufu is the birthplace of Confucius.

> There is a place called Qufu.

(4.1b) 上海 是 / 不是 时尚的 城市。
Shanghai shi / bushi shishangde chengshi.
Shanghai is / isn't modern city.
Shanghai is/isn't a modern city.
$>$ 上海 这个 城市 是 存在 的。
Shanghai zhege chengshi shi cunzai de.
Shanghai, this city, exist -DE.
There is a city called Shanghai.

In English, the commonly used definite descriptions involve singular demonstrative pronouns this, that; proper names e.g. Paris, Caesar, John, singular personal pronouns or impersonal pronouns he, she, I, you, it, singular noun phrases like the table, the old man, the king of France. In Chinese, we can find their translational pairs such as: 这, 那; 巴黎, 凯撒, 约翰; 他, 她, 我, 你, 它; 这(那)张桌子, 这(那)位老人, 法国国王. They all presuppose the existence of the definite descriptions themselves.

(ii) Factive predicates

Chinese has the factive predicates 知道, 明白, 意识到, 后悔, 自豪, 高兴, 难过 etc. which correspond respectively with the English know, understand, realize, regret, be proud, be glad, be sad (see example 4.2a-b).

(4.2a) I regretted telling him the truth.

> I told him the truth.

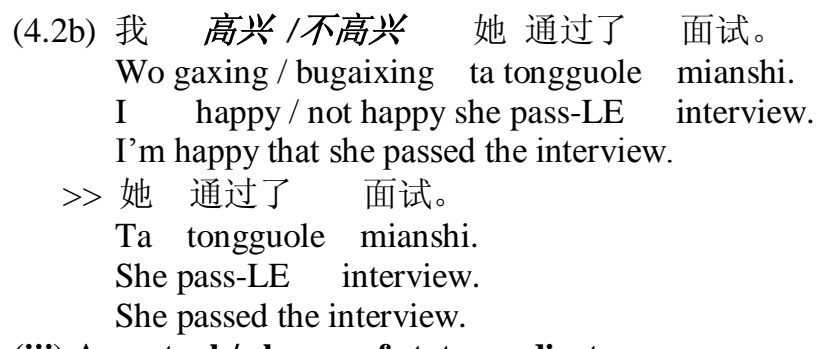

\section{(iii) Aspectual / change of state predicates}

Chang of state predicates involve the starting or stopping of an action. In English we have stop, start, begin, quit / give up, continue, resume, finish. In Chinese, there are also numerous change of state verbs such as 停止, 开始, 放育, 继续, 重新开始, 结束, 离开, 进来.

(4.3a) The search is expected to resume early today.

> The search had begun and then stopped sometime before.

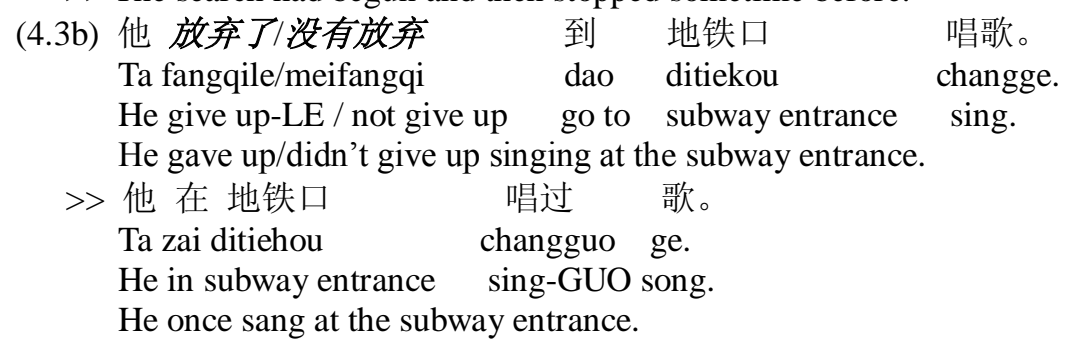

In Chinese, the change of state can also be manifested through some markers like X-起来 (become more...than before) or X-下去(become less...than before) (e.g. 胖起来 become fat/become fatter than before、瘦下去 become slim/become less fat than before, 活跃起来 become active/become more active than before, 沉静下来 become calm/become less active than before, 沸腾起来become excited/become more excited than before, 强壮起来 become

\footnotetext{
${ }^{8}$ Xi Shi (Chinese: 西施) was one of the renowned Four Beauties of ancient China. She was said to have lived during the end of Spring and Autumn Period in Zhuji, the capital of the ancient State of Yue. Xi Shi's beauty was said to be so extreme that while leaning over a balcony to look at the fish in the pond, the fish would be so dazzled that they forgot to swim and sank away from the surface.
} 
robust/become more robust than before, 热闹起来 become lively/become more lively than before) which are termed as inchoative by Wang $\mathrm{Li}$ (Zhao, 2001, p.71) as in the following sentences (4.4).
(4.4) 这个 城镇繁荣起来了。
Zhege chengzhen fanrongqilai-LE.
This town prosperous-LE.
This town became prosperous.
> 这个 城镇原来不繁荣。
Zhege chengzhen yuanlai bu fanrong.
This town in the past not prosperous.
This town was not prosperous in the past.

The change of state in Chinese can also take the form of X(dynamic adjective)- $了$ (LE), indicating that the original situation has changed and the new state has come into being (Lv, 1980, p.260). In this way, the structure as $X$ - $\zeta$ can also be regarded as a type of change of state verbs. See example (4.5).

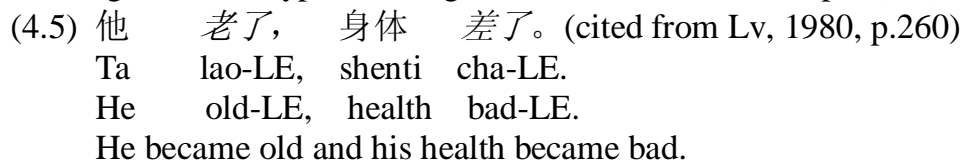

$$
\begin{array}{rll}
\text { > 他之前 不老, 身体 之前 } & \text { 不差。 } \\
\mathrm{Ta} \text { zhiqian bulao, shenti zhiqian } & \text { bucha. } \\
\mathrm{He} \text { in the past not old, health in the past } & \text { not poor. } \\
\text { He was not old and his health was not poor. } &
\end{array}
$$

Unlike English, in Chinese, besides the commonly used change of state verbs, the change of state can be formed by adding change of state markers like $X$-起来 $/ X$-下去, $X$-了 to show the change in the original state.

\section{(iv) Iteratives}

Like English, there are iteratives in that Chinese also trigger presuppositions. These words include 再(zai, agian), 再 (一) 次(zaiyici, again), 又(you, again), 依旧(yijiu, still), 依然(yiran, still), 回到(huidao, return), 不再(buzai, no longer)etc.

(4.6a) John is late again.

>> John was late before.
(4.6b) 女儿 又 给她买了 一件新衣裳。
Never you geita mai-LE yijian xin yishang.
Daughter more for her buy-LE one new dress.
Her daughter bought her one more new dress.

$\begin{array}{llll}\text { > 女儿 曾经 给她 } \text { 买过 } & \text { 新 衣裳。 } \\ \text { Never cengjing } & \text { geita maiguo } & \text { xin yishang. } \\ \text { Daughter once for her buy-GUO new dress. } & \\ \text { Her daughter once bought her new dresses before. }\end{array}$

\section{(v) Implicative predicates}

In Chinese, there is a kind of words whose function in presupposing is similar to that of the implicative verbs in English (like manage indicates try; convince indicates try to make believe; persuade indicates try to make do). These Chinese words are usually made up of two semantic components (Bao, 2005), such as 睡着 (shui zhao), 喝醉(he zui), 赶上(gan shang), 考砸( kao za), 抓到(zhua dao), 看完( kan wan), 洗净(xi jing), where the former component denotes an action and the latter an resultative state. This kind of words asserts the result of some action and presupposes the action, as we can see in the following example.

(4.7) 战士们把饭吃光了/没把饭吃光。

Zhanshimen ba fan chiguang-LE/mei ba fan chiguang.

Soldiers BA- meal eat up/not BA-meal eat up.

The soldiers ate up the meal/didn't eat up the meal.

$$
>\text { 战士们吃饭了。 }
$$

Zhanshimen chifan- LE.

Soldiers eat meal-LE.

The soldiers ate their meal.

In English, there are a lot of such implicative verbs like break, crash, crack denoting both action and result. In Chinese, however, except some dialectical expressions, like Beijing dialect 碎 (here pronounced as /cei/ in Chinese phonetic alphabet, meaning 打破 break), there are fewer single words that can function like English implicative verbs. One possible explanation for this phenomenon is that Chinese is an analytic language. For the lack of inflectional morphemes, Chinese has to use compound words to express action and result of the action. English, on the other hand, though has lost much of the inflectional morphology over the centuries, still conserves many inflectional forms to 
indicate result of action, for example, drunk indicates the result of the verb drink, boiled indicates the result of the verb boil. Here I need to acknowledge that this is only a tentative explanation, which cannot fully account for the phenomenon we talk about here.

(vi) Temporal clauses

Temporal clauses are those headed by before, after, since, while etc. In Chinese we have the equivalents 之前 (before), 之后(after), 自从(since), 在...时(when).

(4.8a) I've been here since I graduated from college.

$>>$ I graduated from college.

(4.8b) 没入 这行 之前, 我 只觉得做 模特 挺 好玩。(CCL)

Meiru zhehang zhiqian, wo zhi juede zuo mote ting haowan.

Not come into this career before, I just think be model fairly interesting.

Before I came into this career, I just thought that being a model was fairly interesting.

> 我做了模特。

Wo zuo-LE mote.

I become-LE model.

I became a model.

(vii) Cleft sentences

There are two kinds of cleft constructions in English. Cleft (see 4.9) and pseudo-cleft (see 4.10).

(4.9) It is / isn't Aya who handles the finances.

> Someone handles the finances.

(4.10) What Aya handles is / isn't finances.

>> Aya handles something.

In Chinese, the corresponding structures are “是某人做了某事/某人是在何时何地以何种方式做的某事 (it is sb who does sth/ it is at a certain time when / at a certain place where / in which way that sb does sth) and 某人做的某事 是......(what sb does is...).” (Lan, 1999, p.13). See example (4.11a-d)

(4.11a) 是班长从老师 那儿借的这本书。

Shi banzhang cong laoshi na'er jie de zhe ben shu.

Is monitor from teacher there borrow this CL book.

It is the monitor who borrowed the book from the teacher.

> 有人从老师那儿借了这本书。

Youren cong laoshi na'er jie-LE zhe ben shu.

Somebody from teacher there borrow-LE this CL book.

Somebody borrowed this book from the teacher.

(4.11b) 班长 是从老师那儿借的 这本书。

Banzhang shi cong laoshi na'er jiede zhe bens hu.

Monitor is from teacher there borrow-DE this CL book.

It is from the teacher where the monitor borrowed this book.

>班长从某个人 那儿借了 这本书。

Banzhang cong mougeren na'er jiele zhe ben shu.

Monitor from somebody there borrow-LE this CL book.

The monitor borrowed this book from somebody.

(4.11c) 班长从老师那儿借的是这本书。

Banzhang cong laoshi na'er jiede shi zhe ben shu.

Monitor from teacher there borrow-DE is this CL book.

It is this book that the monitor borrowed from the teacher.

> 班长从 老师那儿借了 某个 东西。

Banzhang cong laoshi na'er jiele mouge dongxi.

Monitor from teacher there borrow-LE some thing.

The monitor borrowed something from the teacher.

(4.11d) 班长 做的事是从老师 那儿借了这本书。

Banzhang zuode shi shi cong laoshi na'er jiele zhe ben shu.

Monitor do-DE something is from teacher there borrow-LE this CL book.

What the monitor did is borrowing a book from the teacher.

> 班长做了 某件事。

Banzhang zuole moujianshi.

Monitor do-LE something.

The monitor did something.

(viii) Counterfactual conditions 
In English, subjunctive conditionals generally headed by if, unless are typical counterfactual conditionals.

(4. 12 ) If Earth were a flat disk, the shadow would sometimes be oval. (COCA)

>> The earth is not a flat disk.

Note that not all if-clause are counterfactual conditionals. If it snows tomorrow, I'll stay at home does not presuppose that it will not snow tomorrow.

Besides subjunctive conditionals, there are some verbs and constructions in English that function to trigger similar presuppositions as illustrated in examples (4.13-4.15).

(4.13) I wish I'd been clever enough to figure out on my own how to lock down. (COCA)

> I am not clever enough to figure out on my own how to lock down.

(4.14) The students pretended to be interested in the speech.

> The students were not interested in the speech.

(4.15) They behaved as if they themselves were running for office.

> They were not running for office.

In Chinese, there are the corresponding adverbial clauses introduced by 要是(if), 如果(if), 假如(if). See example (4.16).

(4.16) 如果 (要是/假如) 我 是 导演, 我会 选 他演男主角。 Ruguo (yaoshi/jiaru) wo shi daoyan, wo hui xuan ta yan nanzhujue.

If I am director, I will choose him play hero.

If I were the director, I would choose him to play the hero.

> 我 不是 导演。

Wo bushi daoyan.

I not am director.

I'm not director.

\section{CONCLUSION}

In this essay, I first talked the definition of presupposition and then proceeded to discuss the properties of presupposition. Besides the two most widely discussed properties, i.e. constancy under negation and defeasibility, I also addressed two other properties of presupposition: context sensitivity and culture sensitivity. In Section IV, I made a tentative comparative analysis of English and Chinese presupposition triggers, from which we found that while many presupposition-carrying expressions are semantically and pragmatically the same in English and Chinese, the realization of presupposition expression may differ in the two languages. I hope this analysis helps deepen our understanding of the use and interpretation of presupposition.

\section{REFERENCES}

[1] Bao Fang. (2005). Contrastive Study of Presupposition in English and Chinese. (MA thesis) Henan University.

[2] Gazdar, G. (1979). Pragmatics: Implicature, Presupposition, and Logical Form. London: Academic Press.

[3] Green, G. M. (1996). Pragmatics and natural language understanding. $2^{\text {nd }}$ edn. Mahwah, NJ: Laurence Erlbaum.

[4] He Ziran. (1988). A survey of Pragmatics. Changsha: Hunan Education Press.

[5] Huang Yan. (2009). Pragmatics. Beijing: Foreign Language Teaching and Research Press.

[6] Karttunen, L. (1973). Presuppositions of compound sentences. Linguistic Inquiry 4: 169-93.

[7] Karttunen, L. (1974). Presupposition and linguistic context. Theoretical Linguistics 1: 182-94.

[8] Lan Chun. (1999). Xiandaihanyuyusheyinfaxiangchutan [An exploration of the presupposition triggers in Modern Chinese]. Waiyuxuekan [Foreign Language Research] (3): 11-14.

[9] Levinson, S. C. (2003). Pragmatics. Beijing: Foreign Language Teaching and Research Press.

[10] Lv Shuxiang. (1980). Xiandaihanyubabaici [Eight Hundred words in Modern Chinese]. Beijing: The Commercial Press.

[11] Saeed, J. (2000). Semantics. Beijing: Foreign Language Teaching and Research Press.

[12] Sperber, D. \& Wilson, D. (1995). Relevance: communication and cognition. $2^{\text {nd }}$ edn. Oxford: Blackwell.

[13] Soames, S. (1982). How presuppositions are inherited: a solution to the projection problem. Linguistic Inquiry 13: 483-545.

[14] Zhao Shikai. (2001). Yinghanduibiyufalunji [Essays on the Contrastive Study of Chinese-English Syntax: A Cognitive-functional Approach]. Shanghai: Shanghai Foreign Language Education Press.

Lei Kong was born in Qufu, China in 1980. She received her MA degree in linguistics from Nanjing University, Nanjing, China in 2004. Now she is a PHD candidate at Beijing Foreign Studies University, Beijing, China.

She is currently a lecturer in College of Foreign Languages, Qufu Normal University, Qufu, China. Her research interests include pragmatics and Second Language Acquisition. 